\title{
CONSIDERAÇÕES DE USO DE EMBALAGENS PET PARA REFRIGERANTES
}

\author{
Danilo Corrêa Silva \\ PPGDesign - FAAC - Univ. Estadual Paulista "Júlio de Mesquita Filho" \\ danilo@idemdesign.net \\ Luis Carlos Paschoarelli \\ PPGDesign - FAAC - Univ. Estadual Paulista "Júlio de Mesquita Filho" \\ paschoarelli@faac.unesp.br
}

\begin{abstract}
Resumo: Grande parte das Atividades da Vida Diária (AVDs) envolvem a manipulação de embalagens. Produtos de consumo generalizado, como as bebidas refrigerantes devem ter embalagens de fácil acesso e uso, favorecendo o maior número de usuários possível. Esse artigo apresenta algumas considerações sobre o uso e a interação com esse tipo de embalagem. Houve levantamento de dados por meio de um questionário eletrônico, no qual os participantes responderam diversas questões relativas ao uso e a deficiências na interação com esses produtos. Os resultados revelam o modo como essas embalagens são manipuladas e as suas principais deficiências quanto às questões de uso, o que reforça a necessidade de uma avaliação mais aprofundada.
\end{abstract}

Palavras-chave: design, ergonomia, embalagem PET, refrigerantes.

\begin{abstract}
Most of the Activities of Daily Living (ADLs) involve handling packaging. Products of widespread consume, such as soft drinks should have packaging of easy use and access, favoring the largest possible number of users. This paper presents some considerations on the use and interaction with this type of packaging. There was data collection through an online survey, in which participants answered several questions related to the use and deficiencies in the interaction with these products. The results reveal how these packages are handled and their main deficiencies regarding its use, which reinforces the need for further evaluation.
\end{abstract}

Keywords: design, ergonomics, PET packaging, soft drinks. 


\section{INTRODUÇÃO}

Grande parte das Atividades da Vida Diária (AVDs) envolve a manipulação de embalagens. Muitas vezes as embalagens representam o primeiro contato do usuário com o produto, e um fator decisivo no momento da compra. Além disso, uma embalagem desenvolvida corretamente pode se traduzir numa experiência agradável ao indivíduo. Embalagens de consumo generalizado, como as utilizadas no envase de bebidas refrigerantes, não são diferentes, devendo atender a uma série de requisitos da engenharia, de marketing e de design.

Os refrigerantes são bebidas amplamente consumidas em todo o mundo. Em 2006, o Brasil foi o terceiro maior mercado consumidor de refrigerantes do mundo (GUBOLINO, 2007). Esse consumo se dá por consumidores/usuários de diversas faixas etárias e ambos os gêneros, envolvendo indivíduos com as mais diversas capacidades físicas e cognitivas.

O processo de abertura dessas embalagens requer a aplicação de forças de torção a fim de romper o anel de segurança da tampa e realizar a degasagem do produto. Algumas avaliações já foram realizadas no sentido de estabelecer as características cinesiológicas da atividade (CARUS et al., 2006), e também as capacidades biomecânicas de diferentes grupos de usuários ao interagir com essas embalagens (SILVA; PASCHOARELLI; INOKUTI, 2013; SILVA; PASCHOARELLI, 2012).

Este artigo apresenta considerações sobre o uso e a interação com esse tipo de embalagens. A partir dos dados coletados é possível entender como ocorre a interface entre usuário e embalagem, de forma a se estabelecer critérios e procedimentos metodológicos a fim de avaliá-las. Além disso, é fornecido um insight importante sobre a percepção desses sujeitos sobre as principais deficiências no design dessas embalagens.

\section{REVISÃO TEÓRICA}

\subsection{Bebidas Refrigerantes}

Refrigerantes são bebidas carbonatadas não alcoólicas, adoçadas, aromatizadas, acidificadas, coloridas e carbonatadas (gaseificadas) artificialmente. Normalmente, são compostas por xaropes concentrados, aspartame, cafeína e conservantes como ácido benzóico e/ou derivados que são misturados com água carbonatada artificialmente e então envasadas (SÁDECKÁ; POLONSKÝ, 2000). A carbonatação consiste no processo de dissolução de $\mathrm{CO}_{2}$ na bebida, gaseificando-a.

Atualmente, esse tipo de bebida é envasado e comercializado principalmente em embalagens de poli tereftalato de etileno (PET), as garrafas PET. O design desse tipo de embalagem, além das características mercadológicas, deve atender a critérios de engenharia, como a barreira ao escape de gases. Para se alcançar esse fim costuma-se utilizar grandes superfícies lisas no corpo da embalagem e melhorar continuamente 0 sistema de fechamento, incluindo o desenho das tampas, o material, e o mecanismo de vedação (BASTOS, 2006).

Os efeitos desses desenvolvimentos na interação com os consumidores/ usuários ainda é incipiente. Novos sistemas de fechamento podem aumentar a barreira aos gases, porém podem também tornar o processo de abertura mais difícil. 0 mesmo 
acontece no corpo da embalagem, onde superfícies regulares e lisas podem prejudicar o uso por parte expressiva da população.

Quanto ao fechamento, as tampas comumente utilizadas nas garrafas PET (Figura 01) são fabricadas a partir de polipropileno (PP), com anéis retentores de policloreto de vinila (PVC). Esse tipo de fechamento é conhecido como roll on de plástico (BASTOS, 2006). O PP possui elevada resistência mecânica, rigidez e dureza, além de baixa densidade e alta resistência ao calor (BLASS, 2001). O desenho dessas tampas comumente apresenta ranhuras, aumentando a aderência das mãos durante o processo de abertura.

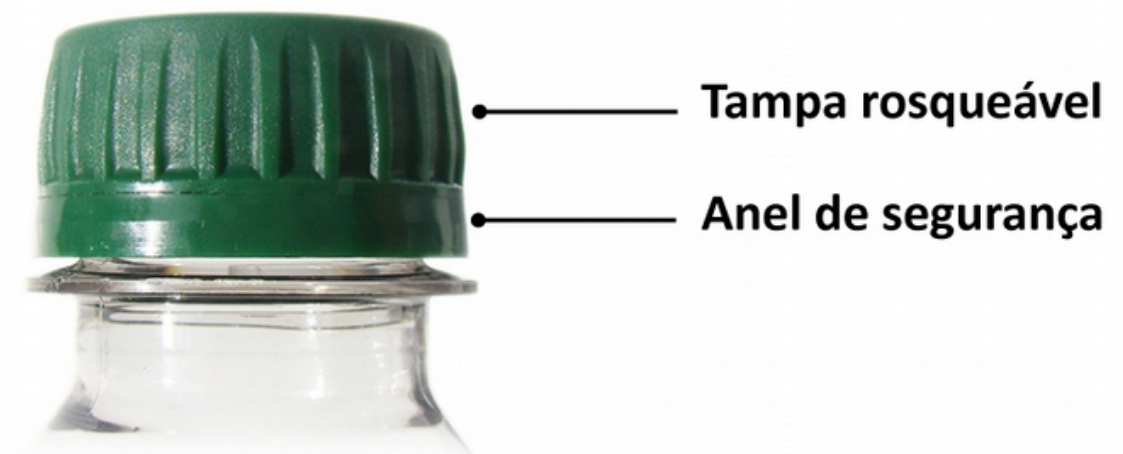

Figura 1. Tampa comumente utilizada em uma garrafa PET.

Adaptado de: Silva (2012, p. 16).

O corpo da embalagem, como mencionado anteriormente, é fabricado em poli tereftalato de etileno (PET), a partir de pré-formas que são aquecidas, estiradas e sopradas no interior de uma forma até que atinjam o formato final. Segundo Bastos (2006), é possível dividir o "corpo" da garrafa PET em três partes: o ombro, o corpo (propriamente dito) e o fundo (Figura 02).

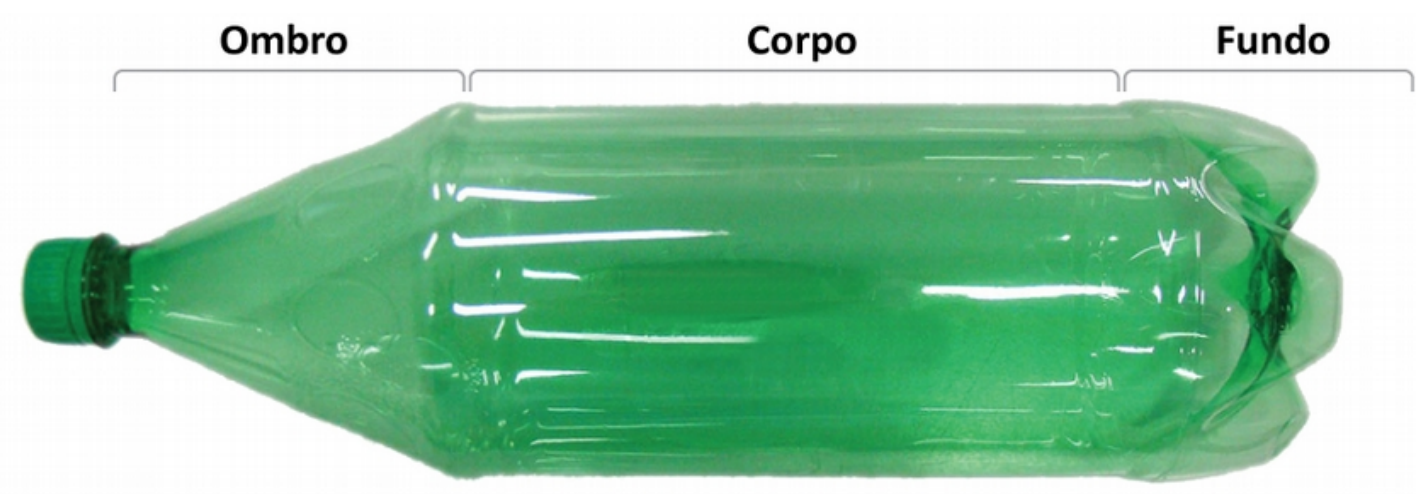

Figura 2. Partes de uma garrafa PET.

Adaptado de: Silva (2012, p. 15).

Como mencionado, devido as suas características de fabricação, essas embalagens podem apresentar diversos formatos, dimensões e texturas. Esses diferentes designs podem influenciar significativamente o processo de abertura desses produtos, uma vez que a distribuição de forças depende da área de contato, da geometria e das características do objeto sendo manipulado (MURALIDHAR; BISHU; HALLBECK, 1999). 


\subsection{Questões de uso de garrafas PET}

Algumas embalagens sujeitas ao manuseio possuem indícios de como os usuários devem manipulá-las. Comumente isso é feito com um estreitamento ou textura diferenciada, que aumenta a estabilidade e firmeza durante a manipulação. 0 mesmo nem sempre é verdadeiro para as embalagens de refrigerantes, pois embora algumas possuam um estreitamento ou textura, em grande parte delas não é possível identificar visualmente onde deve ser efetuada a pega.

Com isso, há a necessidade de entender como os usuários interagem com essas embalagens antes mesmo de avaliá-las. Nesse sentido, Carus et al. (2006) adaptaram dois tipos de embalagens para coletar as forças exercidas por oito voluntários (dois jovens e seis idosos) durante a abertura de dois tipos de garrafas PET de $500 \mathrm{ml}$. No interior dessas embalagens foi inserido um dispositivo que registrou as forças $e$ momentos de força aplicados nos eixos $x$, y e $z$.

$\mathrm{O}$ primeiro tipo de embalagem utilizava sistema de fechamento tampas rollon de plástico (tamper evident), sendo que a abertura significou romper as conexões (bridges) entre a tampa e o anel de segurança. Cada tampa possuía 24 conexões com o anel de segurança, no entanto, em alguns exemplares esse número foi reduzido para 12 , cortando-se os excedentes com um bisturi. O segundo tipo de fechamento era 0 utilizado em bebidas esportivas (pull up - Figura 3), que possuem um selo plástico que deve ser rompido para sua abertura.

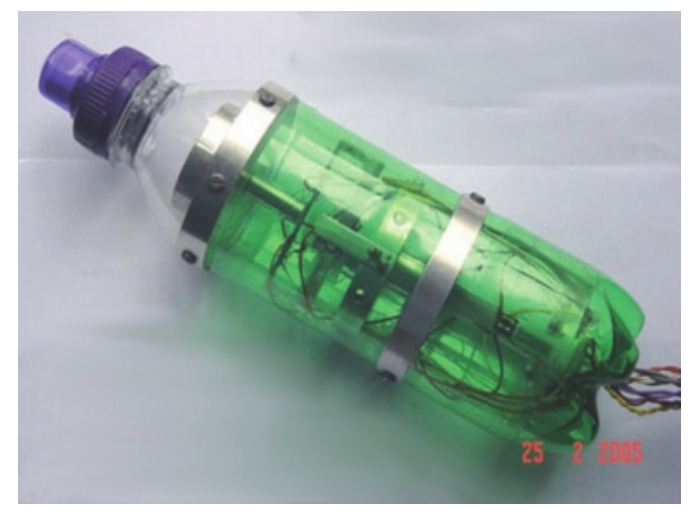

Figura 3. Dispositivo para avaliação cinesiológica da interação com embalagens PET.

Adaptado de: Carus (2006, p. 109).

Esse estudo em particular consistiu em um teste preliminar do sistema desenvolvido pelos autores. Os resultados obtidos nesse estudo mostraram que, embora se esperasse que a força de torção fosse a mesma, os participantes idosos aplicaram aproximadamente o dobro do torque utilizado pelos jovens, para ambas as tampas com 12 ou 24 pontes. Os autores também relatam que os idosos resistiam mais a aplicar o torque "puro" sempre que o percebiam como desconfortável ou até doloroso.

Esse grupo de usuários aplicou forças de forma errática e utilizando mais dedos ou até mesmo a palma da mão para abrir as embalagens, enquanto os jovens utilizaram apenas alguns dedos. Seus resultados corroboram a necessidade de pesquisas mais aprofundadas, uma vez que mesmo com o reduzido número de participantes, foi constatada uma série de atritos com os usuários idosos. 
Silva, Paschoarelli e Silva (2012) realizaram um teste em uma série de garrafas PET de diversos fabricantes e sabores para verificar a força necessária para abrir tais embalagens. Posteriormente, os dados desse estudo foram utilizados para fins comparativos com forças biomecânicas de diversos grupos de usuários, demonstrando que há uma demanda para o redesign dessas embalagens e de seus mecanismos de abertura, de modo a melhorar as questões de uso e acesso desse tipo de embalagem (SILVA; PASCHOARELLI, 2012).

Para o caso específico das embalagens PET, embora seja evidente a necessidade de sua manipulação, a depender do modelo não há um padrão específico de pega para realizar a abertura.

\section{OBJETIVO}

O objetivo desse estudo é coletar e analisar alguns parâmetros da interação dos consumidores ou usuários com embalagens PET para refrigerantes. Esse estudo pretende explorar questões relativas às pegas utilizadas tanto no corpo quanto na tampa dessas embalagens, o nível de dificuldade de abertura e também as técnicas utilizadas para contornar eventuais problemas na interface com essas embalagens.

\section{MATERIAIS E MÉTODOS}

Esse estudo pode ser caracterizado como exploratório e transversal, com a utilização de um questionário eletrônico para levantamento de dados (survey) de usuários de diversas localidades, gêneros e faixas etárias. Participaram dessa etapa 133 indivíduos, sendo 46 do gênero masculino e 87 do gênero feminino.

Os procedimentos metodológicos adotados foram aprovados pelo Comitê de Ética em Pesquisa da Universidade do Sagrado Coração / Bauru - SP (Protocolo 121/2009). Todos os participantes leram e aceitaram as proposições do estudo, que foram devidamente informadas em um Termo de Consentimento Livre e Esclarecido (TCLE), apresentado no início do questionamento.

É importante destacar que esse questionário foi concebido em múltiplas páginas (sequenciais), portanto os indivíduos visualizaram os conjuntos de imagens individualmente. Com isso, buscou-se minimizar uma possível influência das pegas apresentadas em outras etapas. Também não houve a possibilidade de respondê-lo mais de uma vez, visto que houve um filtro de endereço eletrônico. Os participantes que enviaram dados inconsistentes ou incompletos foram descartados da análise.

O questionário utilizado consistiu em uma sequência de sete questões a respeito da interação com as embalagens, como por exemplo o tipo de pega utilizam, estratégias de abertura ou a ocorrência de atritos com esse tipo de produto. Não foi especificado um modelo ou capacidade para o produto, apenas que a embalagem fosse uma garrafa PET para refrigerantes. As questões abrangeram a pega utilizada na tampa, a pega utilizada no corpo, o posicionamento da embalagem durante o processo, a ocorrência e a percepção do nível de dificuldade para abrir esse tipo de embalagem.

Para as questões relativas à pega utilizada, tanto no corpo quanto na tampa, sempre foram exibidas imagens de algumas pegas, e coube ao usuário selecionar aquela de sua preferência. Os dados coletados foram tabulados em planilha eletrônica e analisados por meio de estatística descritiva simples. 


\section{RESULTADOS}

A primeira questão foi dirigida à tampa da embalagem e a preensão utilizada para segurá-la, exibindo uma sequência de cinco fotografias para que os respondentes pudessem associar a sua preferência. Os resultados (Figura 4) indicaram que a maioria dos indivíduos (68\%) realiza a abertura das embalagens adotando uma pega de oposição lateral entre indicador e polegar para realizar a abertura da tampa.

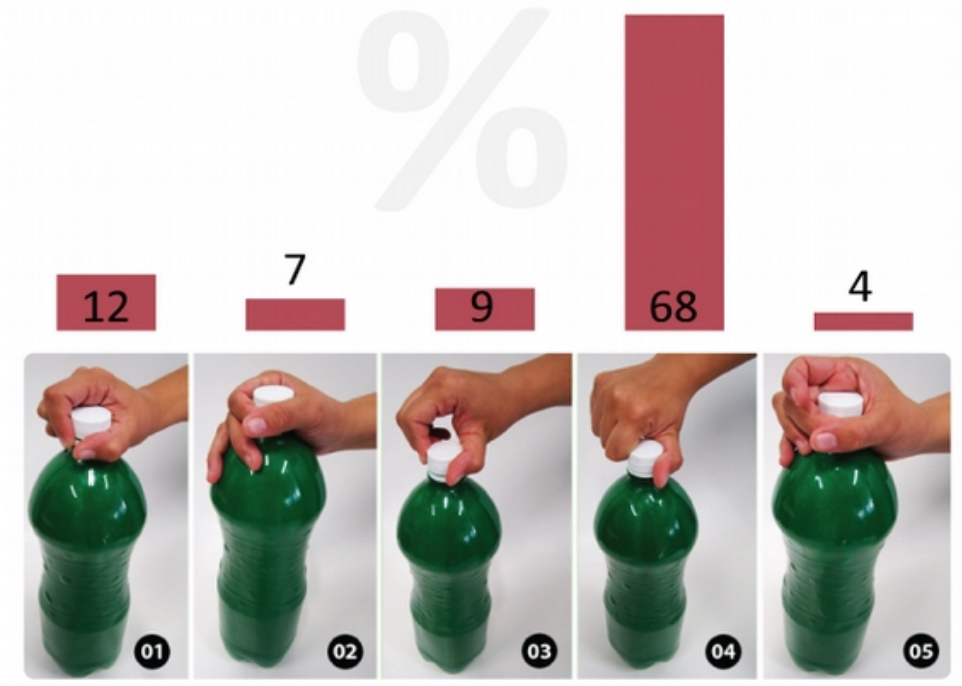

Figura 4. Resultados para a pega utilizada na tampa da embalagem (valores em porcentagem).

Adaptado de: Silva (2012, p. 57).

A segunda questão foi dirigida ao corpo da embalagem e a forma como o usuário o segura. As imagens exibidas exemplificaram a pega no ombro da embalagem, em duas posições do corpo (propriamente dito) ou no fundo da mesma, segundo classificação previamente mencionada. Os resultados apontam que $53 \%$ dos respondentes seguram a embalagem na região do ombro, e $42 \%$ a seguram na região mediana do corpo da embalagem, conforme pode ser visualizado na Figura 5.

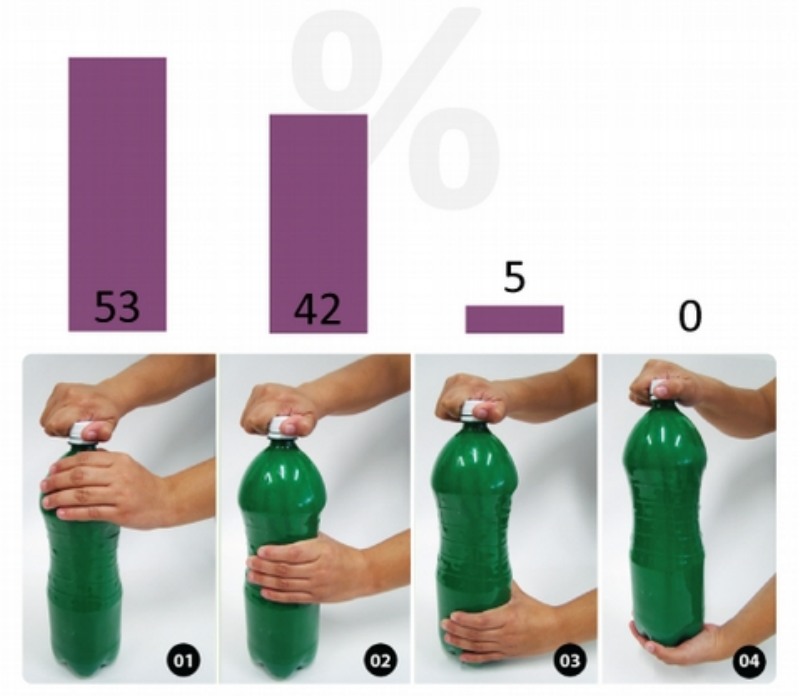

Figura 5. Resultados para a pega utilizada no corpo da embalagem (valores em porcentagem).

Adaptado de: Silva (2012, p. 57). 
A terceira questão se referiu à posição da embalagem quanto à presença ou ausência de uma superfície de apoio. Assim os participantes responderam se preferem abrir a embalagem apoiada em uma superfície (uma mesa, por exemplo), suspensa no ar ou junto ao corpo. A maioria dos respondentes (67\%) prefere apoiar a embalagem em uma superfície para realizar a abertura, apenas $17 \%$ relataram abrir a embalagem suspensa no ar e $16 \%$ preferem abri-la junto ao corpo (Figura 6).

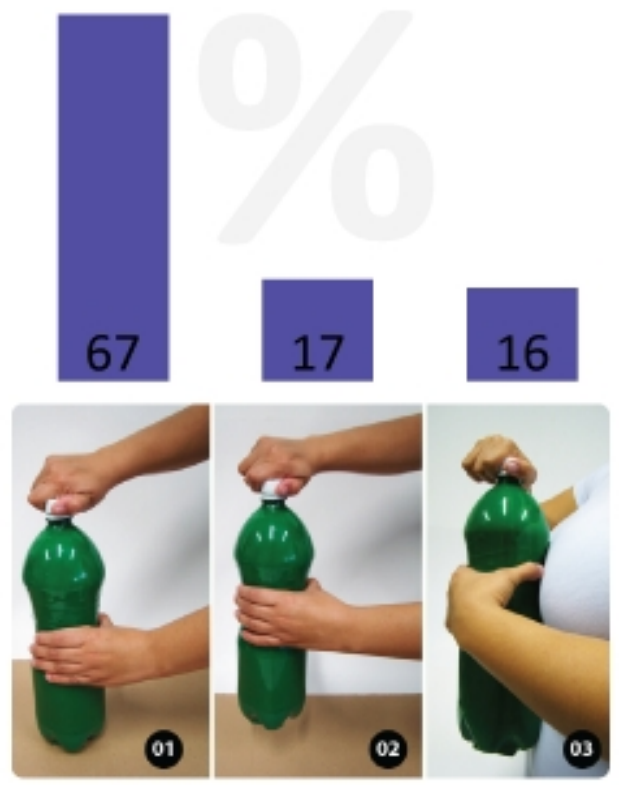

Figura 6. Resultados para a posição relativa da embalagem (valores em porcentagem).

Adaptado de: Silva (2012, p. 57).

A quarta questão se referiu a ocorrência de alguma dificuldade vivida na abertura desse tipo de embalagem. Os resultados confirmam que a grande maioria dos respondentes (84\%) já teve ou tem dificuldades para realizar a abertura de garrafas PET para refrigerantes (Figura 7).

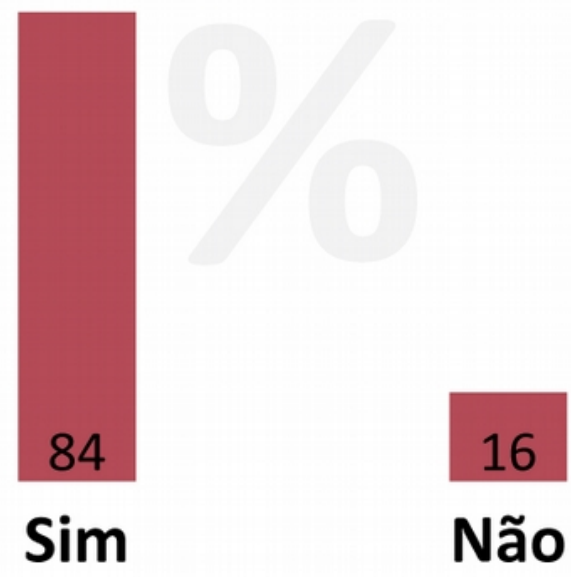

Figura 7. Resultados para a ocorrência prévia de dificuldades (valores em porcentagem).

Adaptado de: Silva (2012, p. 58). 
A quinta questão complementou a anterior ao perguntar qual a situação vivenciada. Os participantes puderam descrever livremente a situação. Nesse caso, a maior dificuldade relatada foi a exigência de força excessiva para realizar a abertura (59 casos $-44 \%$ ), seguida de reclamações a respeito da pega no corpo da embalagem (17 casos -13\%), principalmente devido à umidade e dimensões da embalagem.

$O$ anel de segurança (lacre da embalagem) também foi mencionado por 16 sujeitos (12\% dos respondentes). Defeitos nas conexões entre o anel e a tampa propriamente dita dificultam ou até impossibilitam o rompimento desse dispositivo. Assim, os sujeitos relataram ter de utilizar uma faca para realizar a abertura da embalagem.

Outros relatos envolveram o desconforto causado durante a abertura da embalagem ( 9 casos - 7\%) e até mesmo lesões causadas na pele devido ao excesso de força ou rebarbas na tampa (4 casos - 3\%). Entre as soluções encontradas para contornar tais problemas estão o uso de panos e até facas para realizar a abertura, 0 que aumenta o risco de lesões.

$\mathrm{Na}$ sexta questão foi aberto um espaço para que os participantes manifestassem alguma observação sobre esse tipo de embalagem, apresentassem sugestões ou críticas diversas. Os principais comentários dizem respeito à estabilidade da embalagem, das dimensões do corpo (muito grandes para alguns usuários) e a questão da aderência das mãos, pois a embalagem úmida prejudica a aderência das mãos, aumentando o risco de queda do produto e também prejudicando a torção da tampa.

Na sétima questão os participantes tiveram a oportunidade de classificar o nível de dificuldade para abertura segundo uma escala Likert de 5 âncoras, variando de Extremamente fácil a Extremamente difícil. Mesmo com todos os apontamentos aproximadamente metade (47\%) dos sujeitos associou um nível razoável de dificuldade para abrir a embalagem, enquanto outra porção considerável a classificou como de fácil abertura (34\%), como pode ser visualizado na Figura 8.

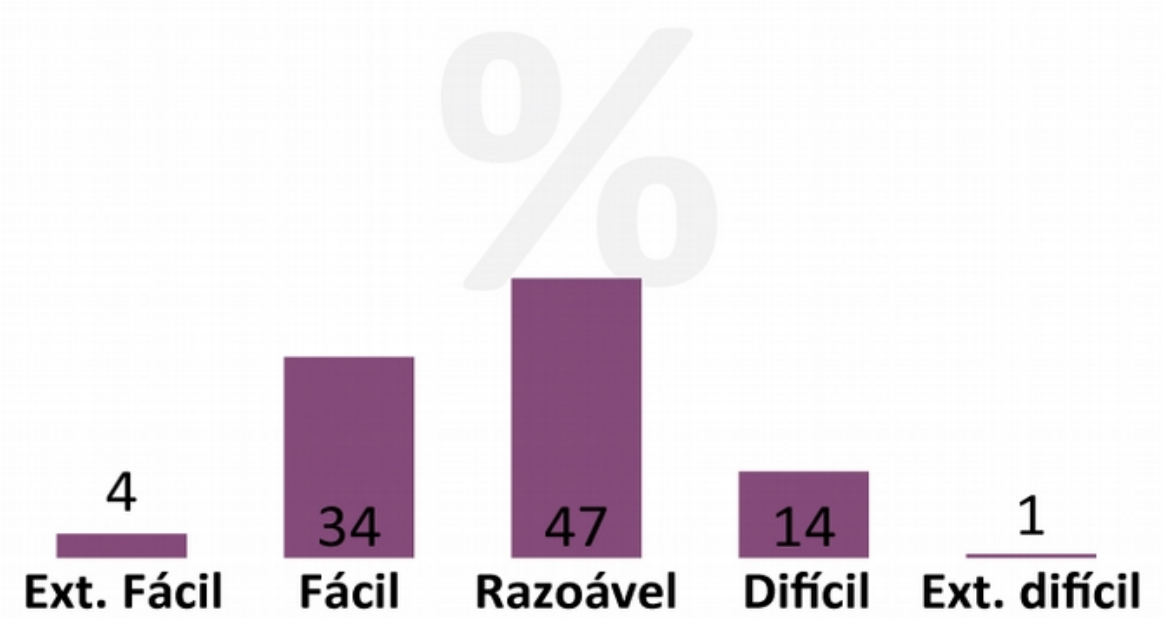

Figura 8. Resultados para o nível de dificuldade para abertura da embalagem (valores em porcentagem).

Adaptado de: Silva (2012, p. 58). 


\section{CONCLUSÕES}

As embalagens fazem parte do cotidiano do homem e ocupam um papel importantíssimo na experiência de uso de muitos produtos de consumo. Quando se trata de alimentos, as embalagens devem possuir grande potencial de conservação do alimento e grande resistência mecânica. Esses fatores muitas vezes acabam por prejudicar questões de uso e acesso desses produtos por parte de uma parcela razoável da população.

Se um consumidor/usuário se sente frustrado ao ser incapaz de abrir uma embalagem, pode se recusar a adquirir o produto novamente, causando impactos nas vendas e na imagem da marca. Da mesma forma, essa incapacidade pode levar o usuário a tomar medidas desacertadas para tentar abrir a embalagem, como por exemplo, utilizar instrumentos perfurantes ou cortantes.

Para as embalagens PET para refrigerantes não é diferente. Além disso, esse produto é consumido por indivíduos com as mais diversas características, desde crianças até idosos, tanto homens quanto mulheres. Esse amplo consumo coloca o Brasil como um dos principais consumidores desse tipo de bebida no mundo. No entanto, estudos sobre como esses usuários interagem com essas embalagens ainda são escassos.

Este artigo apresentou um levantamento de dados sobre o uso e a interação dos usuários com esse tipo de embalagens. Os resultados conferiram a um estudo subsequente (SILVA, 2012) uma base no que diz respeito aos parâmetros e procedimentos metodológicos de avaliação dessas embalagens. Assim foi possível estabelecer as pegas e as condições nas quais todos os indivíduos realizariam os procedimentos.

Os resultados parecem comprovar os atritos existentes em tal interação, com diversos relatos de aplicação de forças excessivas, reclamações a respeito da pega no corpo da embalagem, e também quanto a defeitos no anel de segurança (lacre da embalagem). Todas essas condições acabam por causar desconforto ou até mesmo lesões na pele, devido ao excesso de força ou rebarbas na tampa.

Também foram relatados problemas de estabilidade da embalagem, das dimensões do corpo (muito grandes para alguns usuários) e de aderência das mãos, principalmente aquela ocasionada pela umidade condensada na embalagem. Entre as soluções encontradas para contornar tais problemas estão o uso de panos para suavizar o contato com a pele ou melhorar o atrito com as mãos e até facas para cortar o lacre ou a tampa da embalagem, o que aumenta o risco de lesões.

A partir dos dados coletados é possível entender como ocorre a interface entre usuário e embalagem e seus principais problemas. Além disso, há relatos importantes sobre a percepção desses sujeitos quanto às principais deficiências no design dessas embalagens.

Ressalta-se aqui que uma embalagem desenvolvida corretamente pode se traduzir numa experiência agradável ao indivíduo. Os resultados obtidos indicam a necessidade de melhorar o design de embalagens PET para refrigerantes, tornando esses produtos mais acessíveis, práticos e funcionais.

Os altos índices de atritos e as "soluções" adotadas pelos participantes contribuem para a criação de um panorama da usabilidade desses produtos e enfatizam a necessidade de intervenções. Um design mais eficaz desses produtos pode ser alcançado com características de design que favoreçam o conforto de uso. 


\section{AGRADECIMENTOS}

Esse estudo foi apoiado pela Fundação de Amparo à Pesquisa do Estado de São Paulo (FAPESP - Proc. 2009/13477-4; Proc. 2005/59941-2) e CNPq (Proc. 303138/20106).

\section{REFERÊNCIAS}

BASTOS, H. B. Avaliação de sistemas de fechamento para embalagens de polietileno tereftalato (PET) na retenção de CO2. Campinas: Universidade Estadual de Campinas, 2006.

BLASS, A. Processamento de Polímeros. 2ª . ed. Florianópolis: Editora UFSC, 2001.

CARUS, D. A. et al. Development and validation of a technique to measure and compare the opening characteristics of tamper-evident bottle closures. Packaging Technology and Science, v. 19, n. 2, p. 105-118, mar. 2006.

GUBOLINO, S. I. F. Qualidade físico-química e microbiológica de refrigerantes sabor

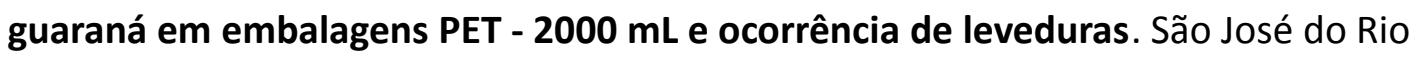
Preto: Universidade Estadual Paulista "Júlio de Mesquita Filho," 2007.

MURALIDHAR, A.; BISHU, R. R.; HALLBECK, M. S. The development and evaluation of an ergonomic glove. Applied ergonomics, v. 30, n. 6, p. 555-63, dez. 1999.

SÁDECKÁ, J.; POLONSKÝ, J. Electrophoretic methods in the analysis of beverages. Journal of Chromatography A, v. 880, n. 1-2, p. 243-279, jun. 2000.

SILVA, D. C. A influência do design na aplicação de forças manuais para abertura de embalagens plásticas de refrigerantes. Bauru: Universidade Estadual Paulista "Júlio de mesquita Filho," 2012.

SILVA, D. C.; PASCHOARELLI, L. C. Usability in the opening of soft drinks packagings: Age influence in biomechanical forces. In: SOARES, M. M.; REBELO, F. (Eds.). Advances in Usability Evaluation Part I. Advances in Human Factors and Ergonomics Series. 1. ed. Boca Raton: CRC Press, 2012. p. 171-180.

SILVA, D. C.; PASCHOARELLI, L. C.; INOKUTI, É. S. Esforço biomecânico e desconforto na abertura de uma embalagem PET para refrigerante13 Congresso Internacional de Ergonomia e Usabilidade de Interfaces Humano Tecnologia. Anais...Juiz de Fora: 2013 SILVA, D. C.; PASCHOARELLI, L. C.; SILVA, J. C. P. Openability of soft drinks PET packagings. Work, v. 41, p. 1346-1351, 2012. 